\title{
Matemática do mundo da vida: abordagem metodológica nos anos iniciais do Ensino Fundamental da Educação de Jovens e Adultos
}

\author{
Célia Souza da Costa ${ }^{1}$ \\ Gisele do Rocio Cordeiro ${ }^{2}$ \\ Liana da Costa Ferreira Bentes ${ }^{3}$
}

\begin{abstract}
RESUMO
A Educação de Jovens e Adultos é uma modalidade de ensino carregada de especificidades, pois o público atendido é diversificado, jovem, adulto e trabalhador geralmente marcados por percalços que dificultaram acesso à educação na idade ideal. Este artigo tem como objetivo discutir como uma abordagem metodológica diferenciada a partir do mundo da vida pode fazer a diferença no ensino da matemática para os estudantes da EJA. Realizou-se uma pesquisa bibliográfica com abordagem qualitativa considerando as contribuições de autores como Januario (2012, 2014 e 2017), Souza (2012), Sampaio (2009), Basegio e Borges (2013) e Hirye et al. (2016), entre outros, procurando enfatizar a importância de uma abordagem metodológica na Educação de Jovens e Adultos, no ensino da Matemática. Concluiu-se que há a necessidade de uma abordagem metodológica diferenciada, no qual o docente poderá adequar a metodologia de acordo com o perfil do alunado e com os saberes prévios, o conhecimento do mundo da vida.
\end{abstract}

PALAVRAS-CHAVE: Matemática. Mundo da vida. Educação de Jovens e Adultos.

\footnotetext{
${ }^{1}$ Doutora em Educação. Instituto Federal do Amapá, Porto Grande, Amapá, Brasil. https://orcid.org/0000-0002-9342961X. celia.amapa@hotmail.com.

2 Doutora em Educação.Centro Universitário Internacional Uninter, Curitiba, Paraná, Brasil. https://orcid.org/00000001-5322-4145.gisele.c@uninter.com.

${ }^{3}$ Especialista em Metodologia do Ensino da Matemática e Física.. Secretaria de Educação do Estado Amapá, Porto Grande, Amapá, Brasil. https://orcid.org/0000-0002-6716-5358.lay.37@ hotmail.com.
} 
Mathematics in the world of life: a methodological approach in the early years of young and adult education

\begin{abstract}
Youth and Adult Education is a teaching modality loaded with specificities, because the audience served is diverse, young, adult and worker generally marked by mishaps that hindered access to education at the ideal age. This article aims to discuss how a differentiated methodological approach from the world of life that can make a difference in teaching mathematics to students in EJA. A qualitative bibliographic research was conducted considering the contributions of authors such as Januario (2012, 2014 and 2017), Souza (2012), Sampaio (2009), Basegio and Borges (2013) and Hirye et al. (2016), among others, looking for emphasize the importance of a methodological approach in youth and adult education in mathematics teaching. It was concluded that there is a need for a different methodological approach, in which the teacher can adapt the methodology according to the student profile and previous knowledge, the knowledge of the world of life.
\end{abstract}

KEYWORDS: Mathematics. World of life. Youth and Adult Education.

Matemática en el mundo de la vida: um enfoque metodológico em los primeiros años de la educación para jóvenes y adultos

\title{
RESUMEN
}

La educación de jóvenes y adultos es una modalidad de enseñanza cargada de especificidades, porque la audiencia atendida es diversa, jóvenes, adultos y trabajadores generalmente marcados por percances que obstaculizaron el acceso a la educación en la edad ideal. Este artículo tiene como objetivo discutir cómo un enfoque metodológico diferenciado del mundo de la vida que puede marcar la diferencia en la enseñanza de las matemáticas a los estudiantes en EJA. Se realizó una investigación bibliográfica cualitativa considerando las contribuciones de autores como Januario (2012, 2014 y 2017), Souza (2012), Sampaio (2009), Basegio y Borges (2013) e Hirye et al. (2016), entre otros. enfatizar la importancia de un enfoque metodológico en la educación de jóvenes y adultos en la enseñanza de las matemáticas. Se concluyó que existe la necesidad de un 
enfoque metodológico diferente, en el que el profesor pueda adaptar la metodología de acuerdo con el perfil del alumno y el conocimiento previo, el conocimiento del mundo de la vida.

PALABRAS CLAVE: Matemáticas Mundo de la vida. Educación de jóvenes y adultos.

$$
* * *
$$

Educar-se é impregnar de sentido cada momento da vida, cada ato cotidiano.

Paulo Freire

\section{Introdução}

O presente trabalho tem como tema a Matemática no mundo da vida: abordagem metodológica nos anos iniciais do ensino fundamental da Educação de Jovens e Adultos (EJA), pois os alunos dessa modalidade de ensino logo que ingressam na escola deparam-se com dificuldades para aprender Matemática, o que causa desmotivação, baixa estima e muitas vezes incentiva a evasão escolar.

Quando nos referimos "a Matemática no mundo da vida”, nos baseamos em Husserl (1969) que elaborou no campo da fenomenologia o termo "o mundo da vida". Missaggia (2018,p.192) diz que na ideia de Husserl "podemos entender mundo da vida como a experiência e o conjunto coerente de vivências pré-científicas [...] em contraste com o mundo propriamente científico”. Em síntese, Missaggia (2018,p.192) assegura que para Husserl, "o mundo da vida [...] diz respeito ainda à vida partilhada com outros sujeitos, na qual todos atuam como pertencentes a um mundo comum".

Para a inserção do mundo da vida na disciplina Matemática é fundamental uma abordagem metodológica diferenciada com conteúdos e situações de aprendizagem adequados às características e necessidades do aluno da EJA. Nesta perspectiva, construiu-se a seguinte indagação que norteia esse trabalho: Como o professor pode enfatizar a Matemática do mundo da vida mesmo no currículo formal? 
Grande é o desafio pedagógico para ensinar Matemática para alunos que já tem conhecimentos constituídos. Esses conhecimentos são de senso comum, resultado das dinâmicas sociais, experiências do cotidiano e subjetividades carregada por cada aluno e aluna da EJA. O ensino da disciplina Matemática na EJA precisa olhar para essa "bagagem vivencial do alunado", sondar quais são os conhecimentos matemáticos pré-científicos que os alunos e alunas detém. Então, o desafio docente é reunir esses conhecimentos prévios e fazer uma relação com a teoria com o objetivo de correlacionar e cristalizar conhecimentos teóricos, que realmente dê sentido ao aprendizado do jovem e do adulto.

A abordagem metodológica a ser desenvolvida pelo professor de Matemática precisa abordar conhecimentos vivos e concretos dos alunos que advém das experiências cotidianas e aliá-los aos conteúdos e conceitos matemáticos para que os alunos e alunas da EJA consigam relacionar o conteúdo escolar à vida no mundo.

Neste contexto, o objetivo primordial desse estudo é discutir como o professor da EJA pode utilizar uma abordagem metodológica diferenciada baseada no mundo da vida nas aulas de Matemática. Para alcançar os objetivos propostos, utilizou-se, a pesquisa bibliográfica com abordagem qualitativa. O primeiro passo metodológico foi buscar artigos científicos da área em periódicos e revistas com a revisão de literatura; o segundo foi realizar um fichamento desses artigos, livros que versam sobre a metodologia de ensino no campo da Matemática e realizar pesquisa em busca de dados que culminou no Gráfico 1 sobre o número de matrícula na EJA; o terceiro passo foi a análise com as confrontações entre os conteúdos dos artigos, livros e fazer aproximações da disciplina Matemática e o mundo da vida dos estudantes.

O texto final foi fundamentado nas ideias e concepções de autores como: Januario (2012, 2014 e 2017), Souza (2012), Nascimento (2013), Romanzini (2010), Griffante et al (2013), Basegio e Borges (2013), Sampaio (2009), Newton (2010), Paula e Oliveira (2012), Hirye et al. (2016). 
http://dx.doi.org/10.14393/ER-v27n2a2020-4

\section{O ensino da Matemática nos anos iniciais do Ensino Fundamental: Modalidade EJA}

A EJA tem como finalidade dar sequência na aprendizagem de jovens e adultos que não conlcuiram seus estudos na idade própria e orientá-los para a sequência de estudos e de trabalho. Estes estudantes ao chegar na escola trazem consigo uma bagagem de experiências vividas que requer uma abordagem adequada a esta condição.

A LDBEN, a Lei de Diretrizes e Bases da Educação Nacional nº 9.394, nos artigos 37 e 38 aborda a Educação de Jovens e Adultos, com a inclusão de novo parágrafo do art.37, proveniente da Lei ${ }^{\circ}$ 11.741, de 16/7/2008:

Art. 37: A Educação de Jovens e Adultos será destinada àqueles que não tiveram acesso ou continuidade de estudos no ensino fundamental e médio na idade própria.

$\S 1^{\circ}$ Os sistemas de ensino assegurarão gratuitamente aos jovens e aos adultos, que não puderam efetuar os estudos na idade regular, oportunidades educacionais apropriadas, consideradas as características do alunado, seus interesses, condições de vida e de trabalho, mediante cursos e exames.

$\S 2^{\circ}$ O Poder Público viabilizará e estimulará o acesso e a permanência do trabalhador na escola, mediante ações integradas e complementares entre si.

Art. 38. Os sistemas de ensino manterão cursos e exames supletivos, que compreenderão a base nacional comum do currículo, habilitando ao prosseguimento de estudos em caráter regular.

$\S 1^{\circ}$ Os exames a que se refere este artigo realizar-se-ão: I - no nível de conclusão do ensino fundamental, para os maiores de quinze anos; I I - no nível de conclusão do ensino médio, para os maiores de dezoito anos.

$\S 2^{\circ}$ Os conhecimentos e habilidades adquiridos pelos educandos por meios informais serão aferidos e reconhecidos mediante exames. (BRASIL, 2008). 
Os dados divulgados pelo Ministério da Educação permitem visualizar o número de jovens que se encontram nesta modalidade educacional. $\mathrm{O}$ gráfico evidencia um total de 3,5 milhões de alunos frequentando a Educação de Jovens e Adultos. O número de matrículas na Educação de Jovens e Adultos (EJA) diminuiu 2,9\% de 2014 a 2018, chegando a 3,5 milhões em 2018. Do total de matrículas declaradas em 2016 e referentes ao Censo de 2018, 81,7\% são provenientes de escolas públicas e 18,3\% de escolas privadas. A rede municipal é responsável por quase metade da declaração (46,9\%), seguida pela estadual, que atende $34,1 \%$ do total. A rede federal participa com $0,7 \%$ do total. Em relação à localização do estabelecimento de ensino, observou-se que, das matrículas declaradas, 88,6\% são de escolas urbanas e 11,4\% de escolas rurais (INEP/MEC, 2019).

GRÁFICO 1 - Número de matrículas de EJA por etapa de ensino - 2014-

2018.

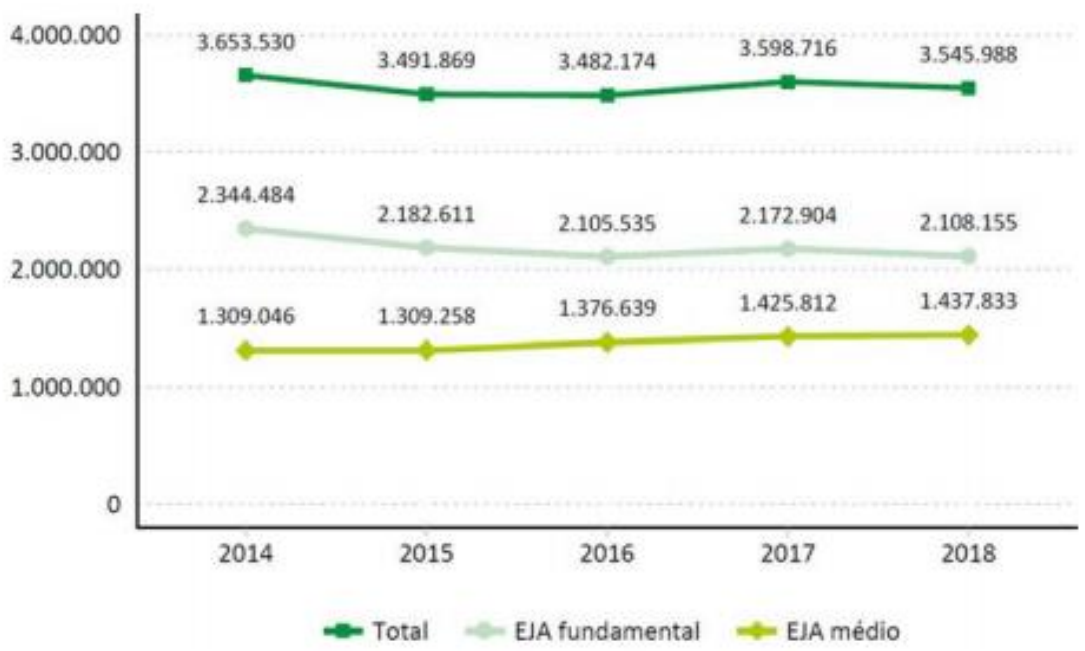

Fonte: INEP/MEC (2019).

Infelizmente, o ensino da disciplina Matemática ao longo dos tempos transformou-se numa das responsáveis pelo fracasso escolar, especialmente na Educação de Jovens e Adultos, o que gera um retrocesso, pois um dos maiores objetivos da EJA enquanto modalidade de ensino é instruir e incluir 
pessoas que por quaisquer motivos não conseguiram concluir o ensino básico na idade regular.

De acordo com Costa $(2013$, p.60,61) a educação de adultos não é recente, surgiu desde o período colonial passando pelo Império com a educação missionária e depois com a formação profissional de artesãos e ofícios. Somente na Constituição Federal instituída por Getúlio Vargas em 1930 tratou-se diretamente sobre a Educação de Jovens e Adultos. Em 1940, a EJA foi consolidada como política nacional. Mas, foi em 1960 que os movimentos sociais asseguraram a alfabetização de adultos como uma ação pedagógica e política do saber popular.

A educação que hoje é denominada de jovens e adultos em outra perspectiva já foi chamada de educação de adultos e de educação popular. A educação popular é um paradigma educacional, se assim se pode dizer, que articula o acesso ao conhecimento a processos emancipatórios. Ela foi desenvolvida no contexto dos movimentos populares e de trabalhadores. Paulo Freire é um dos educadores que adensou o debate da educação popular no Brasil particularmente nos anos de 1960. A educação de adultos tem trajetória secular na educação brasileira, tendo como bandeira central a superação do analfabetismo (SOUZA, 2012, p.36).

Na ótica de Nascimento (2013, p.15), modalidade de ensino de educação de jovens e adultos "surgiu como alternativa à qualificação de mão de obra, com vistas ao atendimento da demanda industrial, onde sua principal função era a de formar indivíduos que agissem como 'máquinas', sem nenhum senso crítico".

Nesse período a única proposta de educação que formasse cidadãos críticos foi desenvolvida pelo educador Paulo Freire, que foi dilacerada pelo regime militar. Inúmeros programas de EJA, após a experiência freireana foram desenvolvidos, mas não eram 
valorizados por parte dos governantes, pois a esses importava a formação de mão de obra e não o conhecimento adquirido (NASCIMENTO, 2013, p.15).

Nesse sentido, Romanzini (2010, p.08) ressalta que o público da EJA é um dos mais atingidos pela lógica capitalista, pois muitas vezes este alunado já está inserido no mercado de trabalho como proletário, em condições de empregado, autônomo como prestador de serviço ou no subemprego. Pregase a seguinte lógica: “[...] nessa modalidade, concentra-se a binômio estudotrabalho sob uma perspectiva de urgência [...] de obter certificação na intenção de uma colocação melhorada". Assim, esvazia-se o caráter da ação crítica, reflexiva e política que deveriam nortear essa modalidade de ensino.

Para Januario (2012, p. 150), o professor pode utilizar várias alternativas recomendadas pela Proposta Curricular para a EJA para reforçar isso.

Que o docente proporcione ao grupo de alunos chance para eles usarem diferentes estratégias e raciocínios para resolver as atividades, que se favoreçam diferentes registros dos alunos jovens e adultos e que estes não fiquem dependentes apenas das anotações e orientações do professor; que o docente possa fazer diferentes observações direcionadas às necessidades de cada aluno, incentivando-o a procurar alternativas de resolução, a selecionar e organizar as informações e a perceber regularidades; e que os conteúdos não sejam abordados de forma fragmentada, mas que haja variação no grau de dificuldade nas situações propostas, partindo de atividades mais simples para chegar em outras mais complexas.

Januario (2012) baseado na Proposta Curricular para a EJA recomenda três estratégias que o professor da disciplina de Matemática pode utilizar em sala de aula. A primeira é utilizar os "raciocínios" na resolução de 
atividades, isso significa fazer uso das experiências do mundo da vida por meio da autonomia. A segunda é que o professor faça um diagnóstico de quais são as necessidades individuais de cada aluno, estimulando a busca pela resolução dos problemas matemáticos; e a terceira que o professor trabalhe a disciplina de forma integrada, primeiro apresentando atividades de menor grau de complexidade e conforme o avanço dos alunos e alunas ir caminhando para questões mais elaboradas.

Já Griffante et al. (2013, p. 05) alertam para a diversidade de uma sala de aula de EJA, portanto o processo ensino-aprendizagem depende de "[...] mais trabalho e dedicação por parte dos professores, pois há necessidade de uma metodologia de ensino, um atrativo que consiga chamar a atenção de todos os alunos e instigar a busca do aprender não é tarefa fácil”. Além disso, é necessário aliar os conhecimentos do mundo da vida dessa diversidade de alunos, que pode variar bastante.

Desse modo, Paula e Oliveira $(2012$, p.16, 44) evidenciam que "uma proposta para a EJA, implica, portanto, clareza dos contextos, das particularidades e dos objetivos". Sendo que um dos maiores desafios dos professores é conseguir mapear quais são as identidades desses alunos, conhecer como essas pessoas atuam, em quais contextos e quais condições.

A diversidade de sujeitos na EJA é uma característica central e altamente definidora dos objetivos políticos-pedagógicos que os programas pretendem alcançar com diferentes grupos e comunidades. Essa diversidade se constitui segundo distintas características que se desdobram principalmente em diferentes interesses, buscas e vocações (PAULA e OLIVEIRA, 2012, p.50).

Nessa perspectiva, Marques (2010, p.10) afirma que a EJA precisa estar articulada com a estrutura pedagógica "com objetivo de criar situações de ensino aprendizagem adequadas as necessidades educacionais de jovens e adultos”. Para Sampaio (2009, p.13), a postura pedagógica perpassa pela formação de professores e professoras, especialmente para atuação na EJA 
que possui especificidades devido o processo educativo estar voltado para o jovem, adulto e trabalhador.

Em verdade, os estudantes da EJA, de uma maneira geral, são indivíduos que foram afetados pelo desenvolvimento socioeconômico desigual de nossa sociedade e que, por essa razão, viram-se submetidos às estratégias de valorização do capital- onde residem as principais causas que os levaram a abandonar a escola. Em suma, é em detrimento de um verdadeiro trabalho de análise da realidade e das condições de existência dos trabalhadoresestudantes que frequentam essa modalidade de ensino- o que colocaria a educação em uma perspectiva crítica e transformadoraque o paradigma da compensação e a visão infantilizadora da EJA que nele está embutida, reforça a ideia de incapacidade das classes populares e reproduz a ideologia das classes dominantes, legitimando, assim, uma estrutura social desigual (BASEGIO e BORGES, 2013, p. 28).

Portanto, devido a essas características que o público da EJA demanda do professor um olhar diferenciado que supra as lacunas educacionais, tanto que Sampaio (2009, p. 13) diz que esse alunado "[...] necessita da adequação da escola e do trabalho pedagógico do professor à vida e às necessidades do aluno adulto, que são diferentes da criança". Eis que se manifesta ao docente o desafio de adequar os conteúdos disciplinares ao mundo da vida para que façam sentido para o discente adulto, especialmente na disciplina Matemática, na qual a defasagem de aprendizado quase sempre é maior.

Assim como a Língua Portuguesa, a educação matemática deve ter o propósito de desenvolver conhecimentos com base na realidade. É importante que o conteúdo seja relacionado à prática social e à interpretação de problemas. Como o conhecimento não é um amontoado de compartimentos, as questões matemáticas devem ser integradas à vida e as outras disciplinas, lembrando que os valores 
humanos podem estar presentes de diversas formas, como quando propomos problemas relacionados ao meio ambiente e aos hábitos dos alunos. Conteúdos infantilizados ou descolados de um contexto não oferecem [...] a possibilidade de adesão dos alunos, o que gera descontentamento, evasão e frustração, tanto para educadores como para educandos (JANEIRO, 2012, p.137-138).

Então, é urgente uma abordagem metodológica diferenciada em todas as disciplinas. A respeito do aprendizado da Matemática de alunos adultos, Fonseca (2009, p.23) explica que existem traços "muito próprios do aprendiz adulto com o conhecimento matemático" com a situação discursiva em que se forja (e que é forjada) seu aprendizado escolar.

Com efeito, as situações de ensino aprendizagem da Matemática permitem-nos momentos particularmente férteis de construção de significados realizados conscientemente pelo aluno. Ou seja, a natureza do conhecimento matemático [...] pode proporcionar experiências de significação passíveis de serem não apenas vivenciadas, mas também apreciada pelo aprendiz. É sob essa perspectiva que o caráter formativo do ensino da Matemática assume, na EJA, um especial sentido de atualidade, quando se dispõe a mobilizar ali, naquela noite, precisamente naquela aula, uma emoção que é presente, que co-move os sujeitos, jovens ou adultos aprendendo e ensinando Matemática, enquanto resgata (e atualiza) vivências, sentimentos, cultura, acrescentando, num processo de confronto e reorganização, mais um elo à história do conhecimento matemático (FONSECA, 2009, p.25).

Sendo assim, Carraher et al. (2010, p.12) ressaltam que "a aprendizagem de Matemática na sala de aula é um momento de interação entre a matemática [...] formal, e a matemática como atividade humana". Então, o professor da EJA deve apropriar-se das vivências matemáticas dos alunos e por meio da interatividade demonstrar que a Matemática formal 
complementa o saber popular, que a Matemática enquanto disciplina está presente no cotidiano.

[...] o ensino de Matemática, assim como todo o ensino, contribuiu (ou não) para as transformações sociais não apenas através da socialização (em si mesma) do conteúdo matemático, mas também através de uma dimensão política que é intrínseca a essa socialização. Trata-se da dimensão política contida na própria relação entre o conteúdo matemático e a forma de sua transmissãoassimilação [...]. Alguns educadores, no intuito de contribuir para as transformações sociais, têm procurado dar um caráter mais politizante ao ensino de Matemática. Tais tentativas tem centrado o ensino em torno de temas relacionados ao custo de vida, à inflação, a cálculos de reajustes salariais, formação de cooperativas, etc. O objetivo aí é o de que a Matemática não seja vista separada dos problemas sociais. Essa vinculação entre a Matemática e as necessidades sociais é realmente importante e tem sido destacada por vários autores (NEWTON, 2010, p.08-09).

Mediante essa realidade do público da EJA, a melhor abordagem metodológica a ser adotada no ensino da Matemática, segundo Hirye et al. (2016, p.145), "direciona-se a ideia de que o aluno viva e aprenda paralelamente e na mesma proporção dos seus desafios que o seu contexto sociocultural [...]”. A Educação Matemática deve estar associada com o mundo da vida, então o professor precisa ter a capacidade de adaptar o currículo. Além de apresentar o conteúdo aos alunos, o docente deve "refletir e discutir acerca do conteúdo matemático que está em ação".

Adaptar o currículo para EJA não é tarefa fácil, requer sensibilidade do professor em corresponder as necessidades discentes e auxílio especialmente da coordenação pedagógica para juntos decidirem as melhores modificações a serem realizadas no currículo escolar da EJA. Para que o "aluno viva e aprenda" concomitantemente, esse é o movimento do "mundo 
da vida", capaz de ser introduzido no currículo formal, pois as experiências, vivências e subjetividades do aluno não podem ser descartadas, o aprendizado formal precisa fazer sentido com o mundo sociocultural.

Sobre o conceito de mundo da vida de Husserl, Missaggia (2018,p.196) menciona que "enquanto atividade humana, o fazer científico é parte do próprio mundo da vida; o problema está, justamente, em que a ciência, com seus pressupostos ocultos, não perceba e tampouco explicite tal vinculação". Essa vinculação se perdeu na constituição do que é ciência, essa crise separou a ciência do mundo da vida, o mundo vivido, experienciado foi substituído pelo mundo de idealidades, Missaggia (2018,p.198) explica que essa mudança vem desde os tempos de Galileu“todas as fórmulas e símbolos das ciências passam, cada vez mais, a criar um distanciamento entre a experiência de realidade tal como se dá no mundo da vida cotidiano e no mundo científico matematizado". Em sala de aula o professor da disciplina de Matemática se depara com essa dicotomia (rigor científico formal matematizado $\mathrm{X}$ mundo da vida), é nesse embate que surge a necessidade de aliar o currículo formal com a Matemática do mundo da vida.

Dentre as várias tendências matemáticas apresentadas por Ceryno (2006), elegemos uma que dialoga mais diretamente com o mundo da vida, e uma abordagem pedagógica estudada por Fonseca (2009). Essa tendência e abordagem respondem a nossa indagação preliminar: como o professor pode enfatizar a Matemática do mundo da vida mesmo no currículo formal ?

A primeira é a corrente histórico-cultural que rompe com o formalismo matemático, Ceryno (2006, p.32) explica que nessa concepção “[...] a Matemática é entendida como um conhecimento vivo, dinâmico e produzido historicamente, conhecimento organizado com linguagem simbólica própria”.

A segunda é a abordagem etnomatemática apresentada por Fonseca (2009, p. 80), ela "procura resgatar a intencionalidade do sujeito cultural manifesta em seu fazer matemático que surge de uma situação- problema”. Outra possibilidade metodológica é incluir a história no ensino da Matemática escolar, pois “[...] é a história que se infiltra na constituição de significados da 
Matemática, obrigando a uma redefinição conceitual nos modos de propor, realizar e analisar as práticas pedagógicas".

Tanto a tendência histórico-cultural do ensino da Matemática quanto a abordagem etnomatemática correspondem saídas metodológicas coerentes para que o professor enfatize a Matemática do mundo da vida no currículo formal. A Matemática, assim como em outras disciplinas tem recorrido ao mundo da vida composta por experiências, vivências e subjetividades formadas e ancoradas nas dinâmicas socioculturais do alunado. Não existe uma proposta metodológica única capaz de atender as demandas dos mais variados contextos escolares. A construção de um currículo mesmo formal que abarque a Matemática do mundo da vida deve ser pensada de forma coletiva (professores, equipe pedagógica, alunos) e estratégica com os elementos do mundo da vida (experiências, vivências e subjetividades).

Sobre isso, Januario, Freitas e Lima (2014, p. 548) asseguram:

Se concebermos a sala de aula como um ambiente que promova a aproximação de saberes matemáticos escolares com não escolares e a concebermos como um ambiente que propicie a enculturação matemática, e se tomamos o currículo apresentado, na forma do livro didático, como um recurso que potencializa o intercâmbio desses saberes, faz-se necessário que esse currículo também promova a enculturação matemática.

Por isso, é importante que o docente da EJA, inclua atividades sociais e culturais no fazer pedagógico Matemático, para propiciar ao aluno a percepção do uso que a sociedade faz do conhecimento matemático. A Matemática está presente em várias situações do cotidiano e fazer essa "ponte" entre o conhecimento empírico e o conhecimento científico é importante para o discente.

Cabe citar ainda que para Januario, Freitas e Lima (2014, p. 554, a relação estabelecida entre professores e materiais curriculares precisa ser tomada como problema de pesquisa. "cujo objetivo seja o de identificar como 
esses profissionais se apropriam das orientações desses materiais".

Como ferramentas socioculturais, os materiais curriculares podem ser recontextualizados pela ação dos professores que, com seus recursos, percebem distintas possibilidades de uso. Por outro lado, os materiais curriculares, com seus recursos, podem possibilitar a (re)construção de sentidos e significados de professores sobre a Matemática e seu ensino a partir de elementos que promovem aprendizagens docentes (JANUARIO, LIMA e MANRIQUE, 2017, p. 422).

Percebemos que um dos pontos cruciais para o estabelecimento da Matemática do mundo da vida no currículo formal depende de movimentos realizados pelo professor que atua na EJA, assim como da equipe gestora da escola e pedagógica em conhecer a realidade de seus alunos, com o objetivo de identificar as necessidades de aprendizagem, para o desenvolvimento de situações que contemplem a realidade desses estudantes e trabalhe com a formação crítica, reflexiva e problematizadora, para que assim haja a adequação curricular do ensino da Matemática. Que o alunado aprenda os princípios fundamentais do saber Matemático na teoria, mas que também ele seja capaz de estabelecer conexões com o mundo vivido, e que o conhecimento matemático seja uma ferramenta para ler, compreender e transformar a realidade.

Foi em busca de resposta para a pergunta problematizadora (como o professor pode enfatizar a Matemática do mundo da vida mesmo no currículo formal ?) que todo o artigo foi direcionado. Assim, a revisão de literatura (artigos e livros) e análises geradas no decorrer da pesquisa com base na abordagem qualitativa a partir dos três passos do caminho metodológico (pesquisa e revisão de literatura; fichamento do material e busca de dados; análise e confrontações dos conteúdos) nos permitiu refletir sobre a Matemática do mundo da vida como uma possível abordagem metodológica nos anos iniciais do Ensino Fundamental da Educação de Jovens e Adultos perpassando pela Filosofia de Husserl com o termo "mundo da vida" até as questões mais específicas que permeiam o ensino da disciplina Matemática. 


\section{Conclusão}

Com o objetivo de discutir como o professor da EJA pode utilizar uma abordagem metodológica diferenciada baseada no mundo da vida nas aulas de Matemática que este trabalho foi desenvolvido. Diante das análises realizadas concluímos que o público atendido pela EJA necessita de uma abordagem metodológica considerando suas especificidades, assim como um currículo diferenciado que direcione o professor a buscar novas formas de desenvolver o trabalho docente por meio do uso de materiais, do senso crítico e da reflexão, por exemplo.

Portanto, é fundamental que a equipe gestora, técnica pedagógica e o professor realize um mapeamento do perfil do alunado, a fim de descobrir em que meio o discente está inserido, quais são suas crenças, experiências e vivências, subjetividades, pois é um erro utilizar a mesma metodologia de ensino da Matemática usual na Educação Infantil e Fundamental para a EJA, o que torna o ensino-aprendizagem infantilizado, algo que não é interessante para jovens e adultos e que potencializa a baixa estima dos alunos de faixas etárias mais avançadas.

Vários são os desafios do professor que atua na EJA. Dentre eles está a necessidade de observar, refletir sobre o alunado. Outro desafio está em agir, modificar, adequar o currículo da EJA de acordo com a realidade dos alunos, com o objetivo de facilitar o processo ensino-aprendizagem associando a educação formal com os saberes adquiridos no mundo da vida.

Sendo assim, a intenção desse trabalho não foi apontar as abordagens metodológicas para o ensino da Matemática como a solução para todos os problemas que acompanham a EJA, ao contrário o propósito foi discutir como uma abordagem metodológica diferenciada a partir do mundo da vida pode fazer a diferença no ensino da Matemática para os estudantes da EJA. Um estímulo para que mais pesquisadores se dediquem na publicação e socialização de investigações no âmbito da Matemática enquanto disciplina. 
Nesse ínterim, cabe ao sistema educacional, ao curso de formação de professores e até mesmo as instituições escolares atentarem para a importância do uso dos conhecimentos prévios dos alunos da EJA no ensino da Matemática, para que o aprendizado gere significado real para esse público e venha contribuir para a transformação social.

\section{Referências}

BASEGIO, L. J.; BORGES, M. C. Educação de Jovens e Adultos: reflexões sobre novas práticas pedagógicas. Curitiba: Intersaberes, 2013.

BRASIL. Lei de Diretrizes e Bases da Educação Nacional. Brasília: Senado Federal, 1996.

BRASIL. Lei n.11.741, de 16 de julho de 2008. Brasília: Senado Federal, 2008. Disponível em: http://www.planalto.gov.br/ccivil_03/_Ato20072010/2008/Lei/L11741.htm. Acesso em 10 nov.2019.

CARRAHER, T. et al. Na vida dez, na escola zero. 15. ed. São Paulo: Cortez, 2010.

CERYNO, E. Conteúdos e metodologias no ensino da matemática I. 2.ed. Florianópolis: UDESC/CEAD, 2006.

COSTA, C. B. Educação de Jovens e Adultos (EJA) e o mundo do trabalho: trajetória histórica e afirmação e negação de direito à educação. Revista Paidéia. Belo Horizonte. Ano 10, n.15,p.59-83. jul./dez.2013. Disponível em http://fumec.br/revistas/paideia/article/viewFile/2403/1448. Acesso em 10 nov.2019.

FONSECA, M.C. F. R.. Educação Matemática de Jovens e Adultos: especificidades, desafios e contribuições. 3 ed. Belo Horizonte: Autêntica Editora,2009.

GRIFFANTE, A. L. et. al. Os desafios da EJA e sua relação com a evasão. XIII Seminário "Escola e Pesquisa: um encontro possível”.2013. Disponível em https://upplay.com.br/restrito/nepso2013/uploads/Projetos_EJA/Trabalho/08_03_25 _Artigo_-_Os_desafios_da_EJA_e_sua_relacao_com_a_evasao.pdf. Acesso em 10 nov.2019.

HIRYE, E. S. et al. Diversidade educacional: uma abordagem no ensino da matemática na EJA. Curitiba: Intersaberes,2016.

HUSSERL, E.. Die Krisis der europäischen Wissenschaften und die transzendentale Phänomenologie. Eine Einleitung in die phänomenologische Philosophie. (Husserliana, vol. VI), edit. BIEMEL, W., 2. ed., Hagen: Martinus Nijhoff, 1969.

INEP. Resumo Técnico: Censo da Educação Básica 2018 [recurso eletrônico]. Brasília : Instituto Nacional de Estudos e Pesquisas Educacionais Anísio Teixeira, 
2019.

JANEIRO, C. Educação em valores humanos e EJA. Curitiba: Intersaberes, 2012.

JANUARIO, G. Currículo de matemática da EJA: análise de prescrições na perspectiva cultural da matemática. Dissertação de Mestrado. Pontifícia Universidade Católica do Paraná, 2012.

JANUARIO, G.; FREITAS, A. V.; LIMA, K. Pesquisas e Documentos Curriculares no Âmbito da Educação Matemática de Jovens e Adultos. Bolema, Rio Claro (SP), v. 28, n. 49 , p. 536-556, ago. 2014.

JANUARIO, G.; LIMA, K.; MANRIQUE, A. L.. A relação professor-materiais curriculares como temática de pesquisa em Educação Matemática. Educ. Matem. Pesq., São Paulo, v.19, n.3, pp.414-434, 2017.

MARQUES, C. E. A construção do conhecimento de jovens e adultos.2010. Disponível em: $\quad$ http://www.unifan.edu.br/files/pesquisa/EJA\%20\%20CRISTIANE\%20EUFRASIO.pdf. Acesso em 10 nov.2019.

MISSAGGIA, J. A noção Husserliana de mundo da vida (ILebenswelt)I: em defesa de sua unidade e coerencia. Trans/Form/Ação, Marília (SP), v. 41, n. 1, p. 191-208, jan./mar.2018.

NASCIMENTO, S. M. Educação de Jovens e Adultos EJA, na visão de Paulo Freire. Monografia de especialização em educação: métodos e técnicas de ensino. Universidade Tecnológica do Paraná .45 f.2013.Paranavaí-Paraná.

NEWTON, D. O ensino de matemática na educação de adultos. 11.ed. São Paulo: Cortez, 2010.

PAULA, C. R.; OLIVEIRA, M. C. Educação de jovens e adultos: a educação ao longo da vida. Curitiba: Intersaberes,2012.

SAMPAIO, M. N. Educação de jovens e adultos: uma história de complexidade e tensões. Revista Práxis Educacional. v. 5. n.7, p.13-27. jul./ dez. 2009. Disponível em http://periodicos.uesb.br/index.php/praxis/article/viewFile/241/253. Acesso em 02 nov.2019.

SOUZA, M. A. Educação de jovens e adultos. Curitiba: Intersaberes,2012.

ROMANZINI, B. EJA-Ensino de Jovens e Adultos e o mercado de trabalho. Qual ensino? Qual trabalho. Universidade Estadual de Londrina, Paraná, 2010. Disponível em: http://www.uel.br/projetos/lenpes/pages/arquivos/aBeatriz\%20Artigo.pdf. Acesso em 01 nov.2019. 